\title{
A PAISAGEM URBANA. NECESSITA-SE COMPREENDER COMO SE FORMA?
}

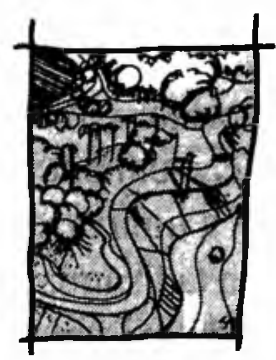

EUGENIO FERNANDES QUEIROGA

Este breve artigo não tem a pretensão de guiar o leitor ao caminho único e certeiro para a compreensão e intervenção na paisagem, trata-se de reflexões sobre a questão da paisagem que não são, em sua maioria, originariamente do autor mas que fazem parte de um sistema de preocupações que o incitam à pesquisa. Preocupações estas que, se não são de desconhecimento público, tem recebido um tratamento que ainda abre espaço para opiniões divergentes, onde, creio, é tentativa deste tex to acrescentar mais um ponto de vista sobre alguns aspectos da produção da paisagem urbana. Espera-se suscitar um debate sobre a importânciadotema, menospeloconteúdoconceitual aqui desenvolvido, mais pelas dúvidas que possam surgir ao leitor em relação a algumas posições defendidas neste artigo, muitas delas fazem parte de um conjunto de indagações ainda não definitivamente esclarecidas.

O presente texto não se coloca como um ponto final sobre a questão da formação da paisagem, éantes um "pré-texto" para o debate, discorre através das preocupações básicas do autor, que o levam à necessidade de estudar o processo de produção da forma urbana.

A primeira preocupação, da qual todas as demais, por mais importantes que sejam, prescindem, é com a cidade. Pode parecer óbvia a ligação entre a necessidade de se pesquisar sobre o processo de produção da paisagem urbana ea cidade, entretanto, como demonstraremos adiante, esta ligação não é tão óbvia assim, aliás, foi algo negligenciada tanto pela academia quanto pelos órgãos de planejamento.

A cidade alvode nossas reflexões nãoéqualquercidade, oque tornaria impossível tentar um estudo sobre um objeto' que é o qualquer. Um segundo argumento que especifica, limita equalifica acidade objeto de nossas preocupaçõesé o grau dealteração da cidade, seja por transformação interna, expansão horizontal ou vertical. A questão da alteração dacidade ou mudança na paisagem é,em princípio, algoque possibilita relacionar, com maior propriedade, este tipo de cidade com o processo de produção da paisagem, já que estamos utilizando a palavra processo como sinônimo de processo histórico onde o sentido de mudança, transformação e especificidade está implícito.

Interessa-nos pois compreender a dinâmica da produção da paisagem justamente das cidades que, num período recente, vem tendo uma expansão e transformação muito 
acentuada. Não que o estudo do processo de produção da paisagem só deva ter como objeto tais áreas urbanas, mas, cremos ser para estes espaços de fundamental importância que secompreenda o processo de produção da forma, como espera-se fique explícito ao fim desta leitura.

Mas quais seriam, enfim, estas cidades? Se mencionamos o fato expansão como uma variável chave, sem dúvida podemos citaras áreas urbanas que vêm tendo uma alta taxa de crescimento populacional nas últimas décadas. Estamos falando, portanto, das cidades que se tomaram metrópoles nos países do Terceiro Mundo, cujo crescimento espantoso é inédito na história da humanidade, boa parte delas cresceram a uma taxa em torno de $5 \%$ ao ano. A título de ilustração, entre a década de 20 e 60, a taxa anual média de crescimento populacional das cidades de Jacarta, México e São Paulo foram respectivamente, $5.8 \%, 5,2 \%$ e $5,1 \%{ }^{2}$. Este crescimentoé muito maior que o verificado na média das demais cidades dos países subdesenvolvidos em questão e por sua vez, tanto a taxa de urbanização, quanto o crescimento populacional dos países do Terceiro Mundo são expressivamente mais acelerados que os verilicados nos países desenvolvidos, no pós-guerra ${ }^{3}$

As causas gerais deste crescimento vertiginoso são já conhecidast, não procedendo, pois, explicá-las aqui em minúcias, entretanto algumas considerações são necessárias a fim de evidenciar as íntìmas relações entre estas expansões urbanas e o atual estágio do sistemacapitalista, relações estas que, diretae indiretamente, sempre interferem na paisagem.

Ainda que várias críticas possam ser feitas às teorias de localização da atividade econômica ${ }^{5}$ é inegável que, para o modo de produção capitalista, há vantagens na concentração espacial das atividades econômicas, este fato é uma das causas da polarização regional. Mas, sobretudo a partir da década de 50 , com a nova fase do sistema capitalista onde despontam com todo o vigor as empresas multinacionais, uma nova relação se faz entre os países desenvolvidos e os subdesenvolvidos. A polarização regional vai enfraquecendo no Terceiro Mundo, já que as empresas multinacionais centralizam suas atividades em um núcleo urbano do país explorado e graças à eficiência dos transportes, que integra o país a este núcleo, é possível que tal área urbana se transforme em pólo nacional cada vez mais poderoso.

Este pólo nacional atrai para si muito mais capital e população que qualquer outra área do território, constituindo-se numa metrópole nacional com um crescimento que desequilibra ainda mais a rede de cidades do país, destruindo a solidariedade regional e criando um mercado nacional polarizado. Éobvio que esta lógica de crescimento das metrópoles nacionais tende a diminuir à medida em que aumentam as descconomias de escala, cntretanto tal fenômeno, que hoje já se percebe na metrópole de São Paulo, 
não significa a possibilidade de atenuar, a curto prazo, os desequilíbrios regionais; mas sim a expansão em um pequeno raio destas atividades econômicas, transformando a metrópole nacional em megalópole nacional, como se está verílicando no caso paulista, com o crescimento das regiões de Campinas, Vale do Paraíba, Sorocaba e Litoral.

Afora as graves conseqüências deste processo para o desenvolvimento das áreas polarizadas pela metrópole nacional, voltemos nossa atenção para o pólo, pois como já foi dito é nele que se encontra a maior dinâmica sócioeconômica e portanto aí está a paisagem mais dinâmica. Ainda que as várias metrópoles do Terceiro Mundo guardem muitas características comuns, dado serem produtos do sistema capitalista mundial, as especificidades histórico-geográficas de cada uma delas não nos permitiriam generalizar todas as considerações que faremos adiante. Sendo assim, passemos a análise para São Paulo. Mas por que São Paulo e não, por exemplo, Cingapura? Simplesmente porque o autor conhece um pouco São Paulo e não Cingapura.

A preocupação com São Paulo hoje, sua paisagem, sua gente, sua vida, decorre do vertiginoso crescimento ocorrido nesta metrópole a partir de sua industrialização, se sua riqueza advém deste período, sua pobreza e seus maiores problemas também. A pequena cidade da virada do século cresceu muito rapidamente, atendendo aos interesses das atividades econômicas principais (setores industrial, imobiliário, comerciale financeiro) edas necessidades de suas classes mais favorecidas. Comoconsequiência da ausência de uma política urbana a médio e longo prazos (salvo o Plano Avenidas de Prestes Maia, cujas críticas não cabe aqui discutir) a metrópole já nos anos 60 se apresentava cheia de problemas, sem uma estrutura alternativa a velha estrutura rádioconcêntrica, que por mais salurada e fora da escala da metrópole, ainda hoje permanece e se fortalece (vide as obras do Corredor Sudoeste da Administração Jânio Quadros).

A região metropolitana de São Paulo cresce hoje, de forma similar a quase trinta anos atrás, através de: loteamentos periféricos para classe baixa; loteamentos "distantes da poluição e junto ao verde dos campos e matas" com ótimo acesso para o desfrute das classes mais altas; verticalização demolindo até bairros inteiros ou ocupando vazios urbanos deixados estrategicamente pela especulação; favelização crescente: a sempre tímida intervenção direta do poder público no setor habitacional: implantação indusIrial junto às estradas; pulverização das atividades comerciais outrora centrais para as áreas mais adequadas ao setor imobiliário e às classes dominantes; etc.

Um dos resultados deste crescimento feilo de maneira atomizada e segundo interesses quase individuaisé uma mancha urbana amorla, paisagensdesinteressantes, pobresem espaços livres realmente adequados ao lazer e convívio, pobres em valorização do sítio, 
onde a caótica ocupação individual de cada lote, feita sem respeitar o entorno, leva a uma homogeneização, a uma monotonia da paisagem.

Ainda que possamos responsabilizar, em grande medida, os interesses econômicos das classes favorecidas, muito bem representadas no Estado, pelo rumo que vem tomando os espaços da metrópole paulista, cabe indagar qual tem sido a posiçãode nós, arquitetos (o termo é empregado lalu sensu, se refere pois, ao paisagista, urbanista, programador visual, etc.) perante este processo. Dos arquitetos têm partido, sem dúvida, muitas e pertinentes críticas, mas ainda que se deixe de lado o fato de que a calegoria, muitas vezes, é conivente com os interesses do setor imobiliário (não raro pela impossibilidade prática de ser contra, a curto prazo), é necessário analisar nossa atividade a nível do planejamento urbano. Isto pois. a despeito de não determos o poder político e econômico, podemos (e muito, aliás, já conquistamos nos últimos vinte anos) intervir, enquanto técnicos, nas regulamentações de uso e formas de ocupação do lote, além das disposições mais gerais da organização da cidade a nível de planos direlores (lamentavelmente pouco considerados pelas Administrações).

Da análise das propostas e resuliados obtidos das leis de zoneamento urbano não só do município de São Paulo, mas de vários outros que compõem a regiño metropolitana, constata-se uma alarmante despreocupação com a paisagem urbana em todos os níveis. Esta despreocupação é o que permite produzir a paisagem monólona e tão sem qualidades verificadas, em grande parte, na região metropolitana de São Paulo. Os mecanismos de que dispōem estes zoneamentos não são suficientes para induzir a um desenho urbano interessante e rico em apropriações, ao contrário, muitas vezes até impossibilitam que tal desenho apareça, dadas as exigências de recuos, as taxas de ocupação e coeficiente de aproveitamento do solo, inviabilizam gabaritos de altura e nunca são ajustadas segundo as potencialidades do sítio, gerando uma forma urbana confusa e, muitas vezes, caótica.

Ao privilegiar os aspectos de viabilidade de crescimento urbano (estabelecendo limites de ocupação), de qualidade ambiental das edilicaçōes (estabelecendo recuos e taxas de ocupação que permitem ventilação e iluminação sulicientes) e de separação de funções (proibindodeterminados usos, em certas zonas) nota-se quão fortemente marcadas pelo ideário moderno-racionalista são as propostas de zoneamento da metrópole paulista. O edifício isolado, as zonas industriais, habilacionais, etc. são elementos da ideologia do funcionalismo que tanto influenciou nossa categoria profissional; mas, no caso paulista, o zoneamento tão influenciado por esta ideologia não serve e até desestimula, por paradoxal que seja, o surgimento de uma paisagem urbana similar à preconizada pelo ideário moderno. 
Mas por que haveria o planejamento de se preocupar com a paisagem? Não seria uma análise somente estélica (ideológica) a crítica para com a Paisagem de São Paulo? Em que tal paisagem constitui-se num problema tão sério? Existem vários argumentos que responderiam a estas questões, limitar-nos-emos a expor sinteticamente uma posição que nos parece suficiente e significativa.

Todas as atividades humanas prescindem de um espaço, através do reconhecimento e a apropriação destes espaços o homem tem condições de se desenvolver, transformando o espaço que era uma base potencial da alividade em algo íntimo, conhecido. Estabelecendo valores e significados ao espaço o homem o transforma em "lugar"૪

A metrópole paulista é um espaço suporte de um imenso complexo de atividadẹs humanas, entretanto seus habitantes não a têm como um lugar complexo cuja compreensão facilmente se traduz em uma gama enorme de apropriações de seus espaços. Para o paulistano, São Paulo não é um lugar complexo mas sim complicado, haja visto que cada cidadão "conhece" somente parte da metrópole e dela usufrui uma parte ainda menor e menor ainda sĩo os lugares vividos cotidianamente. Várias são as razões que levam a este comportamento, uma das mais importantes é a própria paisagem urbana; faltam-lhe mais referenciais; faltam-lhe, a nível de "bairros" identidades, devido às mudanças que não cessam de ocorrer no uso, nas formas, na população local e devidoà homogeneizaçãodeextensasáreas; faltam-lheespaços livres em todas as escalas que possibilitem uma utilização mais rica e numerosa.

Falta, pois, à paisagem da Grande São Paulo, clareza e qualidade, atributos imprescindíveis para que a população tenha uma maior compreensão dos espaços da metrópole e, portanto, possa deles melhor se apropriar. Éatravés. também, de uma maior vivência dos lugares, trocando informações entre si, que uma população cleva seu grau de exigência em relação aos espaços humanos, melhorando, se satisfeito o novo grau de exigência, sua qualidade de vida. A buscapor uma qualidade de vidamelhoréo objetivo final do planejamento.

Dado que as transformaçōes na paisagem metropolitana ainda estão longe de terminar é possível e mais que isso, é preciso intervir a fim de criar uma paisagem com as tão necessárias qualidades já mencionadas. Esta intervenção, como se sabe nãoé facilmente posta em prática. Na criação de uma nova cidade, já é penosa e muitas vezes mal sucedida a tentativa de criar uma paisagem urbana legível, rica e adequada à sociedade; numa metrópole com formas, processos e interesses já estabelecidos, alterar qualitativamente a paisagem requer muito mais que a genialidade do traço de um único arquiteto. 
A tarefa é árdua, mas deve ser feita. Para que seja executada com eficiência (com o mínimo de custos sociais convertidos em máximos benefícios para esta mesma sociedade) é preciso conhecimento da realidade metropolitana ${ }^{7}$, dentro desta realidade é fundamental, o que não significa ser suficiente, conhecer os processos pelos quais se realiza a produção do espaço urbano. Muito já se pesquisou a respeito ${ }^{8}$, sobretudo encarando-se o espaço via as categorias: função estrutura e processo". Tais pesquisas são de uma importância vital e básica, mas a questão da produção do espaço urbano não se esgota no estudo das calegorias mencionadas, é preciso relacioná-lascom acategoria forma ${ }^{10}$, sem a qual estar-se-ia negligenciando, novamente, a questão da paisagem.

É preciso, pois, compreendermos o processo de produção da paisagem urbana. Entretanto, o conceito de paisagem envolve o conceito de imagem (uma mesma forma é visıa - interpretada - como paisagens diferentes ${ }^{11}$ em função de quem a observa, dada a carga cultural do observador, a maneira e a freqüência da observação) e contém alguns elementos pouco manipuláveis pelo homem, tais como: a luminosidade em ambientes abertos, a abóbada celeste, o tempo, etc. ${ }^{12}$

Tais características da paisagem dificultam a análise e podem desviarnos do objetivo central que passa por compreender os processos sócioculturais que produzem, sobre 0 suporte físico, as formas urbanas, formas estas que junto com outros elementos fazem parte da paisagem urbana. Portanto, dada a natureza da forma urbana (devido sua materialidade concreta), nela recai, por fim, nossa atenção. O processo de produção da forma urbana é pois, uma das totalidades da realidade metropolitana mais necessárias a se compreender.

Concluindo, se reconhecemos que a paisagem metropolitana de São Paulo padece de uma série de deficiências e compreendemos a importância de possuirmos formas urbanas mais adequadas às atividades humanas, devemos inserir em nossos planos urbanísticos uma posição clara e eletiva sobre a paisagem desejada. Tal posição será factivel ou não na medida em que soubermos adequar os mecanismos e instrumentos legais de planejamento à realidade em questão, pois se queremos alterar uma realidade é preciso conhecê-la. Dentro desla perspectiva, um dos mais importantes aspectos da realidade metropolitana que necessitamos conhecer é, sem embargo, o processo de produção da forma urbana ${ }^{13}$.

\section{NO'TAS}

(1) O terno "objeto" não está sendo utilizado como a categoria "objeto" empregada pelos positivistas (ver Émile Durkheim, As Regras do Método Sociológico, São Paulo: Nacional, 1968). Mas assumida a inpossibilidade de total separação entre sujcito e objcto (vide Karl 
Manheim. Ideologia e Utopia. Rio de Janeiro: Zahar, 1976), utilizamos o vocábulo com o sentido de campo limitado e, de certa forma, determinado.

(2) Cf. SANTOS, Milton. Manual de geografia urbana. São Paulo: Hucitec, 1981.

(3) ldem, ibidem.

(4) Idem, ibidem. Sobre São Paulo vide SINGER, Paul. Desenvolvimento econômico e evolução urbana. São Paulo: Nacional, 1977.

(5) Ver a respeito AZZONI, Carlos R. Evolução das teorias de localização da atividade econômica. In: Economia urbana - localizaçāo e relaşōes setoriais. Organizadores Longo, Rizzieri, São Paulo, IPE-USP, 1982.

(6) Vide YI-FU, Tuan. Espaşo e Lugar. A Perspectiva da Experiência. São Paulo: Difel, 1983.

(7) Realidade esta que transcende aos aspectos locais, fazendo parte de uma totalidade concreta muito mais ampla que chega a ser internacional. A respeito da questão da realidade e totalidade. Vide KAREL Kosik. Dialética do Concrelo. São Paulo: Paz e Terra, 1985,

(8) Vide VILLAÇA, Flávio J. M. A estrutura territorial da metrópole sul brasileira. Árcas residenciais e comerciais. São Paulo, 1978. Tese (Doutoramento), Departamento de Geografia da FFLCHUSP.

(9) Vide SANTOS, Milton. Espaço e método, São Paulo: Nobel, 1985.

(10) Idem, ibidem.

(11) Vide MEINING, D. W. The beholing eye: ten versions of the same scene. Landscape Architecture, jan. 1976.

(12) Sobre elementos do espaço ver ECBO, Garret. Urban Landscape Design, Nova York: Mc-Graw Hill, 1964.

(13) Agradeço ao Grupo de Disciplinas Paisagem e Ambiente da FAUUSP pela convivência, sem a qual, muito pouco teria a dizer. De maneira alguma isto me isenta da total responsabilidade pelas incorreções contidas no texto. 